\title{
Body mass index and the risk of infections in institutionalised geriatric patients
}

\author{
Thomas E. Dorner ${ }^{1,2} *$, Franz Schwarz ${ }^{3}$, Alexander Kranz ${ }^{4}$, Wolfgang Freidl ${ }^{1}$, Anita Rieder ${ }^{2}$ and \\ Christoph Gisinger ${ }^{5,6}$ \\ ${ }^{1}$ Institute of Social Medicine and Epidemiology, Medical University Graz, Austria \\ ${ }^{2}$ Institute of Social Medicine, Centre for Public Health, Medical University Vienna, Austria \\ ${ }^{3}$ Austrian Academy of Sciences, Vienna Institute for Demography, Austria \\ ${ }^{4}$ Department of Radiation Oncology, Medical University Vienna, Austria \\ 5 'Haus der Barmherzigkeit', Geriatric Long-Term Care Facility, Austria \\ ${ }^{6}$ Department of Clinical Medicine and Biotechnology, Danube University Krems, Austria
}

(Received 3 April 2009 - Revised 6 January 2010 - Accepted 9 January 2010 - First published online 8 March 2010)

The objective was to examine the effect of BMI on the incidence of various infectious diseases in institutionalised, geriatric subjects. In a retrospective cohort study we analysed medical records of 619 patients aged 75 years and older (mean age 87.6 (SD 6.4) years) who were treated in a geriatric hospital in Vienna, Austria. The total incidence rate of infection in this population was 0.80 per person-year. The most frequent infections were urinary tract infections ( $0 \cdot 30$ per person-year), followed by infections of the lower respiratory tract $(0 \cdot 19$ per person-year), diarrhoea $(0 \cdot 12$ per person-year) and other infections ( 0.20 per person-year). Incidence risk ratios were obtained by a multiplicative Poisson regression model. There was a J-shaped curve in the incidence of infections recorded by BMI with a nadir at $27-28 \mathrm{~kg} / \mathrm{m}^{2}$. Compared with the reference group with a BMI of $24-27.9 \mathrm{~kg} / \mathrm{m}^{2}$, subjects with a lower BMI had a higher incidence rate of infections. The incidence risk ratios, adjusted for sex, age and chronic diseases, were $1.62\left(95 \%\right.$ CI 1.21, 2.17) for those with a BMI of $<20 \mathrm{~kg} / \mathrm{m}^{2}$ and $1.84(95 \%$ CI $1.40,2.42)$ for those with a BMI of $20-23.9 \mathrm{~kg} / \mathrm{m}^{2}$. However, also patients with a BMI of $28 \mathrm{~kg} / \mathrm{m}^{2}$ and above had a higher incidence rate of infections, with an incidence risk ratio of $1.54(95 \%$ CI 1.07, 2.22). These results show that both underweight and obesity are associated with a higher risk of infections in institutionalised geriatric patients.

Malnutrition: Obesity: Pneumonia: Urinary tract infections: Underweight

In long-term care facilities, infections are a common cause of morbidity and mortality ${ }^{(1)}$. Infections in the elderly are more frequent and severe than in the general population ${ }^{(2)}$. Individuals in nursing homes have a higher risk of acquiring infectious diseases compared with community-dwelling individuals, and pneumonia is the leading cause of morbidity and mortality in this group ${ }^{(3)}$.

Among geriatric subjects, a low BMI and unintentional weight loss are a great mortality threat ${ }^{(4)}$. A high BMI and obesity, on the other hand, are an emerging phenomenon not only in the general community, but also in geriatric populations $^{(5)}$ and in nursing homes ${ }^{(6)}$. A high BMI has been shown to be associated with a lower mortality risk in older subjects: in the Longitudinal Study of Aging among 7527 participants aged 70 years and older, individuals with a BMI of $28.5 \mathrm{~kg} / \mathrm{m}^{2}$ and more had a significantly lower risk for death compared with those with a BMI between 18.5 and $28.4 \mathrm{~kg} / \mathrm{m}^{2(7)}$. Among geriatric in-patients with a mean age of 81.5 years, the age-adjusted mortality rate decreased from 24 to 9.6 per 100 patient-years from the highest BMI quartile $\left(\right.$ BMI $\left.\geq 28 \mathrm{~kg} / \mathrm{m}^{2}\right)$ to the lowest $\left(\mathrm{BMI}<22 \mathrm{~kg} / \mathrm{m}^{2}\right)^{(8)}$. However, in subjects aged 65 years or older, a BMI $>27 \mathrm{~kg} / \mathrm{m}^{2}$ has been shown to be associated with an increasing mortality risk $^{(9)}$. Obesity in older subjects is also associated with increased functional limitations and poor quality of life ${ }^{(10,11)}$, and obese older individuals are admitted more frequently to nursing homes compared with those who are not obese ${ }^{(12)}$.

Data about the influence of BMI on the incidence of infections are scarce. In the present analysis we wanted to determine the frequency of infections among institutionalised geriatric patients. The aim of the present study was to clarify the impact of the baseline BMI on the development of infectious diseases in this particular population. It was not the purpose to investigate underlying mechanisms of infectious diseases.

Abbreviation: UTI, urinary tract infection.

* Corresponding author: Dr Thomas Dorner, fax +43 316380 9665, email thomas.dorner@medunigraz.at 


\section{Methods}

\section{Subjects and data}

The data in the present study are based on a retrospective analysis of medical records of patients who were treated at the geriatric hospital 'Haus der Barmherzigkeit' in Vienna, Austria. This hospital is specialised in the medical and nursing support of multi-morbid geriatric patients who require a high level of care. Medical records were documented by the ward physician with the use of electronic patients' charts ('Geripas') (13) and included variables such as age and sex, diagnoses of chronic diseases, and anthropometric parameters such as body height and body weight which were measured routinely by the ward staff. Body weight was measured with a regularly calibrated person weight scale or a chair scale. Body height was assessed in standing or lying position with a measuring tape. Furthermore the development of acute diseases that warrant medical interventions, such as infectious diseases, were also documented by the ward physician. As a general rule, infections of the lower respiratory tract were diagnosed clinically and verified by X-ray, urinary tract infections (UTI) were diagnosed by nitrite positive stick in the case of clinical suspicion, usually followed by urine culture, and diarrhoea was diagnosed clinically, optionally followed by stool culture.

For this analysis, only subjects aged 75 years and above with a complete set of data regarding body weight, body height, age and period under observation were included. Incidence rates were computed as number of events per person-year. We examined in particular the association between BMI and the occurrence of several types of infections (infections of the lower respiratory tract, UTI, diarrhoea, and other infections). For this purpose four BMI groups were set up $\left(<20,20-23.9,24-27.9\right.$ and $\left.\geq 28 \mathrm{~kg} / \mathrm{m}^{2}\right)$. We did not use $\mathrm{WHO}^{(14)}$ or National Institutes of Health ${ }^{(15)}$ cut-off points, in order to allow a sufficient sample size in each BMI category.

\section{Statistics}

Descriptive statistics were applied; mean values are presented with standard deviations. The main outcome measures were incidence risk ratios that were obtained by a multiplicative Poisson regression model, which was fitted as a log-linear regression (a log link and a Poisson error distribution), with an offset equal to the natural logarithm of exposure time. These incidence rates are presented with $95 \%$ CI.

To estimate and visualise the precise pattern of the association between BMI and incidence of infection, we employed a generalised additive model with a log link and a Poisson error distribution. In the model the dependent variable $y$ was a function of the predictor $B M I$, but their association was not necessarily linear:

$$
\log (E(y) / P T)=c+f(B M I) .
$$

The term $\mathrm{E}(y)$ divided by person time (PT) represents the estimated incidence rate and $c$ is the constant in the model. Generalised additive models allow the fitting of any predictor with a non-parametric smoothing function; hence, no a priori assumption regarding the pattern of the predictor's effect is required. The following covariables for applying the multivariate Poisson models were used: sex (female), age ( $\geq$ the median of 88 years) and the presence of nine different chronic medical conditions. All calculations were carried out using the $R$ Language and Environment for Statistical Computing and Graphics, version 2.7.2 (http://www.r-project.org/).

Table 1. Baseline characteristics of 619 institutionalised geriatric patients aged 75 years and older (Number of subjects and percentages or mean values and standard deviations)

\begin{tabular}{|c|c|c|c|c|c|c|}
\hline \multirow[b]{2}{*}{ Patient characteristics } & \multicolumn{2}{|c|}{ Men $(n$ 109) } & \multicolumn{2}{|c|}{ Women ( $n$ 510) } & \multicolumn{2}{|c|}{ Total $(n 619)$} \\
\hline & $n$ & $\%$ & $n$ & $\%$ & $n$ & $\%$ \\
\hline \multicolumn{7}{|l|}{ Age (years) } \\
\hline Mean & \multicolumn{2}{|c|}{84.4} & \multicolumn{2}{|c|}{$88 \cdot 3$} & \multicolumn{2}{|c|}{$87 \cdot 6$} \\
\hline SD & \multicolumn{2}{|c|}{$6 \cdot 1$} & \multicolumn{2}{|c|}{$6 \cdot 3$} & \multicolumn{2}{|c|}{$6 \cdot 4$} \\
\hline \multicolumn{7}{|l|}{ BMI $\left(\mathrm{kg} / \mathrm{m}^{2}\right)$} \\
\hline Mean & \multirow{2}{*}{\multicolumn{2}{|c|}{$\begin{array}{c}22.0 \\
3.5\end{array}$}} & \multirow{2}{*}{\multicolumn{2}{|c|}{$\begin{array}{c}22.4 \\
4.7\end{array}$}} & \multicolumn{2}{|c|}{$22 \cdot 3$} \\
\hline SD & & & & & & \\
\hline$<20$ & 29 & $26 \cdot 6$ & 167 & $32 \cdot 7$ & 196 & 31.7 \\
\hline $20-23.9$ & 53 & $48 \cdot 6$ & 174 & 32.5 & 227 & $36 \cdot 7$ \\
\hline $24-27 \cdot 9$ & 21 & $19 \cdot 3$ & 106 & $19 \cdot 8$ & 127 & 19.5 \\
\hline$\geq 28$ & 6 & 5.5 & 63 & $12 \cdot 4$ & 69 & $11 \cdot 1$ \\
\hline \multicolumn{7}{|l|}{ Number of chronic diseases } \\
\hline Mean & \multicolumn{2}{|c|}{$2 \cdot 4$} & \multicolumn{2}{|c|}{$2 \cdot 4$} & \multicolumn{2}{|c|}{$2 \cdot 4$} \\
\hline SD & \multirow{2}{*}{\multicolumn{2}{|c|}{$1 \cdot 1$}} & \multicolumn{2}{|c|}{$1 \cdot 1$} & \multicolumn{2}{|c|}{$1 \cdot 1$} \\
\hline Chronic diseases & & & & & & \\
\hline Dementia & 77 & $70 \cdot 6$ & 377 & 73.9 & 454 & $73 \cdot 3$ \\
\hline IHD & 42 & 38.5 & 207 & $40 \cdot 4$ & 249 & 40.2 \\
\hline Cerebrovascular disease & 44 & $40 \cdot 4$ & 110 & $21 \cdot 6$ & 154 & 24.9 \\
\hline Parkinson's disease & 10 & $9 \cdot 2$ & 20 & 3.9 & 30 & 4.8 \\
\hline Cancer & 33 & $30 \cdot 3$ & 73 & $14 \cdot 3$ & 106 & $17 \cdot 1$ \\
\hline Chronic obstructive pulmonary disease & 12 & 11.0 & 43 & 8.4 & 55 & 8.9 \\
\hline Diabetes & 17 & $15 \cdot 6$ & 86 & $16 \cdot 9$ & 103 & $16 \cdot 6$ \\
\hline Osteoporosis & 9 & $8 \cdot 3$ & 187 & $36 \cdot 7$ & 196 & 31.7 \\
\hline Osteoarthritis & 19 & 17.4 & 134 & $26 \cdot 3$ & 153 & 24.7 \\
\hline
\end{tabular}




\section{Results}

The records of 784 subjects were available. Excluded were 124 patients for failure to meet the inclusion criterion of at least 75 years of age. Also excluded were forty-one subjects because of missing data; thus a total of 619 subjects were included for further analyses. These subjects were followed for a mean period of 368 (SD 209) d (median $398 \mathrm{~d}$; range $2-595 \mathrm{~d}$ ), resulting in a total exposure time of 624.6 person-years, 94.2 male and 530.4 female person-years. There were 188.1 person-years of subjects with a BMI of under $20 \mathrm{~kg} / \mathrm{m}^{2}, 231.1$ person-years of subjects with a BMI between 20 and $23.9 \mathrm{~kg} / \mathrm{m}^{2}, 134.8$ person-years with a BMI between 24 and $27.9 \mathrm{~kg} / \mathrm{m}^{2}$, and 70.6 person-years of subjects with a BMI equal to or greater than $28 \mathrm{~kg} / \mathrm{m}^{2}$.

The baseline characteristics of study participants such as age, BMI and prevalence of chronic diseases for men, for women and in total are presented in Table 1. During the period of observation a total of 500 infectious diseases were recorded, resulting in an incidence rate of 0.80 per personyear. The incidence rates were 0.97 per person-year for men and 0.77 per person-year for women. Older subjects $(\geq 88$ years) had a slightly higher incidence rate of infections (0.82 per person-year) compared with younger subjects ( 0.77 per person-year). Of the 500 infections recorded, 120 were infections of the lower respiratory tract, 185 were UTI, seventy-three cases of diarrhoea and 122 other infections. The corresponding incidence rates were $0.19,0.30,0.12$ and 0.20 per person-year, respectively. The incidence rates for the men were $0.25,0.47,0.07$ and 0.17 and for the women $0 \cdot 18,0 \cdot 27,0.12$ and 0.20 per person-year, respectively.
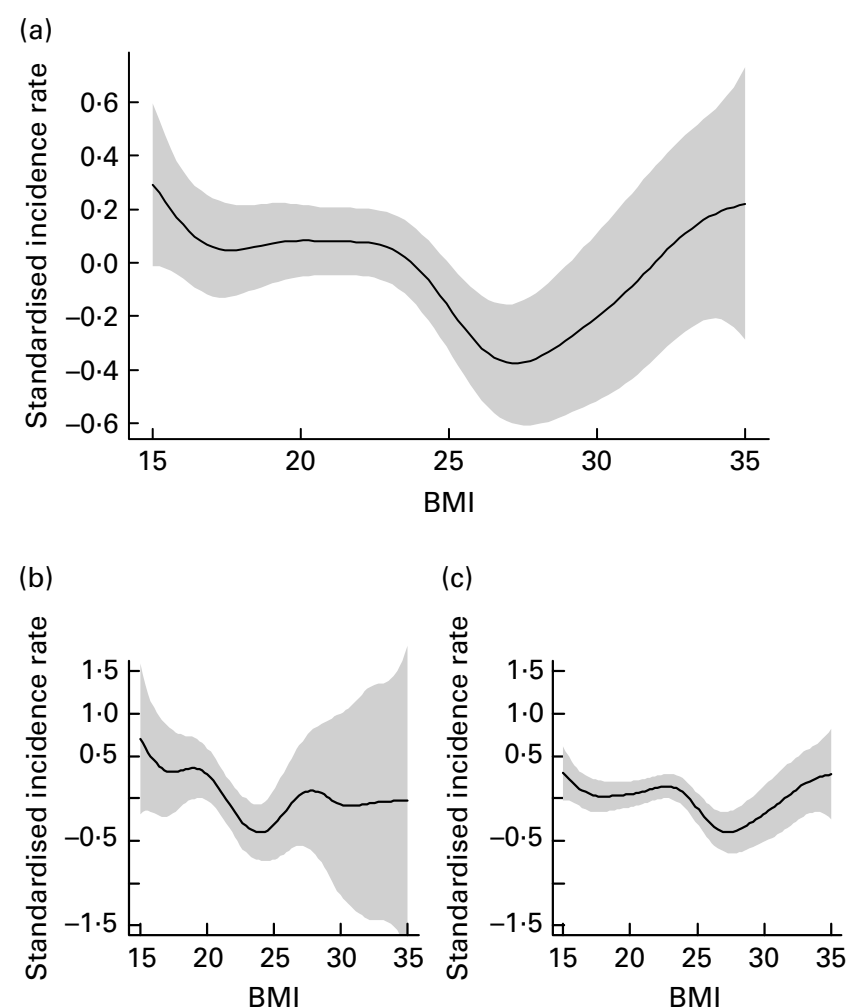

Fig. 1. Estimated association between BMI and incidence for infections (-), with 2 SE confidence band $(\square)$ in institutionalised geriatric patients aged 75 years and older. (a) All subjects; (b) men; (c) women.
The association between BMI and incidence of infections is depicted in Fig. 1. Patients with a BMI between 24 and $27.9 \mathrm{~kg} / \mathrm{m}^{2}$ had the lowest incidence rate for infections and were defined as the reference group. Subjects with a lower BMI had a higher incidence rate of infections, with raw incidence risk ratios based on univariate Poisson models of 1.67 (95\% CI $1.25,2.21)$ for those with a BMI of $<20 \mathrm{~kg} / \mathrm{m}^{2}$ and $1.90(95 \%$ CI $1.45,2.49)$ for those with a BMI of $20-23.9$ $\mathrm{kg} / \mathrm{m}^{2}$. However, also those patients with a BMI of $28 \mathrm{~kg} / \mathrm{m}^{2}$ and above had a higher incidence rate of infectious diseases with a raw incidence risk ratio of 1.49 (95\% CI 1.04, 2.14).

Controlling for sex, age and chronic diseases had little impact on the above described picture, as presented in Table 2, based on multivariate Poisson models. Also after adjusting, the data showed a significantly higher incidence risk ratio for infections in the BMI groups of $<20,20-23.9$ and $\geq 28 \mathrm{~kg} / \mathrm{m}^{2}$. Female sex was a protective factor for UTI. A higher age was associated with a higher chance of diarrhoea. Dementia was associated with a higher risk of 'other infections'. Parkinson disease was significantly associated with all infections and with infections of the lower respiratory tract, and chronic obstructive pulmonary disease was also associated with infections of the lower respiratory tract.

\section{Discussion}

Depending on the BMI, the incidence of infections in institutionalised geriatric patients shows a J-shaped curve, with a high incidence rate in underweight and normal-weight subjects, but also an increasing incidence with increasing BMI in obese subjects. The nadir of this curve was found at a BMI of about $27-28 \mathrm{~kg} / \mathrm{m}^{2}$. This curve resembles the J-shaped curve of mortality depending on the BMI in the general population. Most analyses show that in the general population both a low and a very high BMI are associated with increased overall as well as cause-specific mortality ${ }^{(16-18)}$. The nadir of this J-shaped curve was found at a BMI of 23.5 to $24.9 \mathrm{~kg} / \mathrm{m}^{2}$ in men and 22.0 to $23.4 \mathrm{~kg} / \mathrm{m}^{2}$ in women ${ }^{(16)}$. For older individuals, also a U- or J-shaped mortality curve depending on the BMI has been described with the difference that this curve is shifted to the right. In the elderly population (aged 50-80 years), the nadir of the mortality curve was found at a BMI of $28.2 \mathrm{~kg} / \mathrm{m}^{2}$ for men and $27.1 \mathrm{~kg} / \mathrm{m}^{2}$ for women $^{(19)}$. In the population aged 65 years or older, overweight was not found to be associated with a higher mortality risk, whereas mortality increased with a BMI of $31 \mathrm{~kg} / \mathrm{m}^{2}$ and higher ${ }^{(9)}$.

In our analyses we found an incidence rate of infection of 0.80 per person-year, the most frequent infections being UTI. In a French care unit housing residents with a mean age of 82 years, the incidence rate of infections was more than three times higher (7.6 per 1000 bed-days); most of them, here too, were UTI. In this analysis, subjects with infections had an altered nutritional status ${ }^{(20)}$.

After controlling for age, sex and chronic diseases, the same pattern for the incidence rate of infections could be observed as in the analyses of the crude data. It is interesting to see that age and most chronic diseases, for example, the diagnosis of diabetes mellitus, did not influence the incidence of infections in our population. This fact is likely to be an indicator for the good glycaemic control in patients with diabetes in our cohort. 
Table 2. Risk, based on multivariate Poisson models, for total infections, infections of the lower respiratory tract, urinary tract infections, diarrhoea and other infections in institutionalised geriatric patients aged 75 years and older, adjusted for sex, age and chronic diseases

(Incidence risk ratios (IRR) and 95\% confidence intervals)

\begin{tabular}{|c|c|c|c|c|c|c|c|c|c|c|}
\hline \multirow[b]{3}{*}{ Characteristics } & \multicolumn{10}{|c|}{ Infections } \\
\hline & \multicolumn{2}{|c|}{$\begin{array}{l}\text { Total infections } \\
\quad(n 500)\end{array}$} & \multicolumn{2}{|c|}{$\begin{array}{l}\text { Lower respiratory } \\
\text { tract infections } \\
(n 120)\end{array}$} & \multicolumn{2}{|c|}{$\begin{array}{l}\text { Urinary tract infec- } \\
\text { tions }(n 185)\end{array}$} & \multicolumn{2}{|c|}{$\begin{array}{l}\text { Diarrhoea } \\
\quad(n 73)\end{array}$} & \multicolumn{2}{|c|}{$\begin{array}{l}\text { Other infections } \\
\qquad(n 122)\end{array}$} \\
\hline & IRR & $95 \% \mathrm{Cl}$ & IRR & $95 \% \mathrm{Cl}$ & IRR & $95 \% \mathrm{Cl}$ & IRR & $95 \% \mathrm{Cl}$ & IRR & $95 \% \mathrm{Cl}$ \\
\hline \multicolumn{11}{|l|}{ BMI $\left(\mathrm{kg} / \mathrm{m}^{2}\right)$} \\
\hline$<20$ & 1.62 & $1 \cdot 21,2 \cdot 17$ & 1.94 & $1 \cdot 10,3.42$ & $2 \cdot 27$ & $1.32,3.92$ & 0.65 & $0.33,1.28$ & 1.59 & $0.86,2.96$ \\
\hline $20-23.9$ & 1.84 & $1.40,2.42$ & 1.63 & $0.93,2.86$ & $2 \cdot 80$ & $1.68,4.67$ & 0.82 & $0.44,1.51$ & 2.09 & $1.17,3.72$ \\
\hline $24-27 \cdot 9$ & 1 & Reference & 1 & Reference & 1 & Reference & 1 & Reference & 1 & Reference \\
\hline$\geq 28$ & 1.54 & $1 \cdot 07,2 \cdot 22$ & 0.69 & $0.27,1.78$ & 2.39 & $1 \cdot 26,4.56$ & 1.20 & $0.55,2.63$ & 1.99 & $0.96,4.15$ \\
\hline Female & 0.82 & $0.64,1.05$ & 0.85 & $0.52,1.40$ & 0.62 & $0.43,0.90$ & 1.42 & $0.62,3.22$ & 1.06 & $0.61,1.86$ \\
\hline Aged $\geq 88$ years & 1.04 & $0.86,1.25$ & 0.96 & $0.65,1.40$ & 0.91 & $0.67,1.23$ & 1.86 & $1 \cdot 11,3 \cdot 12$ & 0.97 & $0.66,1.43$ \\
\hline \multicolumn{11}{|l|}{ Chronic diseases } \\
\hline Dementia (yes) & $1 \cdot 21$ & $0.96,1.52$ & 1.21 & $0.76,1.94$ & 1.02 & $0.71,1.47$ & 1.03 & $0.58,1.82$ & 1.83 & $1.09,3.09$ \\
\hline IHD (yes) & 1.08 & $0.90,1.30$ & 1.42 & $0.98,2.06$ & 0.93 & $0.69,1.26$ & 1.06 & $0.66,1.71$ & 1.06 & $0.74,1.54$ \\
\hline Cerebrovascular disease (yes) & 0.99 & $0.80,1.22$ & $1 \cdot 12$ & $0.74,1.70$ & 0.80 & $0.56,1.14$ & 1.23 & $0.73,2.08$ & 1.00 & $0.65,1.54$ \\
\hline Parkinson's disease (yes) & 1.46 & $1.03,2.07$ & $2 \cdot 32$ & $1 \cdot 25,4.29$ & 1.27 & $0.72,2.23$ & 0.72 & $0.17,3.00$ & 1.35 & $0 \cdot 65,2 \cdot 82$ \\
\hline Cancer (yes) & 0.88 & $0.69,1.14$ & 1.31 & $0.83,2.06$ & 0.82 & $0.54,1.25$ & 0.72 & $0.34,1.52$ & 0.70 & $0.40,1.22$ \\
\hline $\begin{array}{l}\text { Chronic obstructive } \\
\text { pulmonary disease (yes) }\end{array}$ & $1 \cdot 28$ & $0.96,1.70$ & $2 \cdot 29$ & $1.43,3.67$ & $1 \cdot 16$ & $0 \cdot 71,1.89$ & $1 \cdot 30$ & $0 \cdot 62,2 \cdot 74$ & 0.55 & $0.24,1.25$ \\
\hline Diabetes (yes) & 1.02 & $0.79,1.31$ & 1.29 & $0 \cdot 79,2 \cdot 11$ & 0.77 & $0.49,1.20$ & 1.07 & $0.58,2.00$ & $1 \cdot 11$ & $0.68,1.82$ \\
\hline Osteoporosis (yes) & 0.95 & $0.78,1.16$ & 0.93 & $0.61,1.40$ & 0.77 & $0.55,1.09$ & $1 \cdot 10$ & $0.68,1.79$ & 1.20 & $0.82,1.76$ \\
\hline Osteoarthritis (yes) & 0.96 & $0.78,1.18$ & 0.71 & $0.44,1.14$ & 1.01 & $0.72,1.43$ & $1 \cdot 18$ & $0.72,1.94$ & 1.00 & $0.66,1.50$ \\
\hline
\end{tabular}

There was a sex difference in the incidence rate of UTI: men were unexpectedly more frequently affected by UTI than women. Usually the prevalence ratio between women and men in older individuals is $2: 1^{(21)}$. Common reasons for UTI in the elderly are mechanical changes in the bladder, urothelial changes, lack of oestrogen in postmenopausal women, prostatic hyperplasia in men ${ }^{(2)}$, but also urinary catheters ${ }^{(22)}$. The higher chance for UTI in our sample could be due to the fact that more men than women were supplied with urinary catheters, or to a high prevalence of prostate hyperplasia in men; data to confirm these assumptions are, however, missing. Dementia was also found to be associated with a higher rate of infections. This also is in line with the findings of previous studies $^{(23,24)}$.

Among institutionalised geriatric patients, nutrition-related problems are very common. The extremes of the BMI range can be regarded as indicators for nutritional problems in that undernutrition can lead to sarcopenia and a low BMI, while overnutrition can lead to obesity and a high BMI. Malnutrition, a chronic state in which a combination of varying degrees of over- and undernutrition and inflammatory activity change body composition ${ }^{(25,26)}$, is associated with increased mortality in very old hospitalised patients ${ }^{(24)}$. Malnutrition is also a risk factor for infections in older individuals ${ }^{(2)}$, and a poor nutritional status is an indicator of adverse prognosis for pneumonia in the elderly population ${ }^{(27)}$.

Undernutrition is defined as a state of energy, protein or other specific nutrient deficiency which produces a measurable change in body function and is associated with worse outcome from illness ${ }^{(28)}$. In undernourished subjects, the missing micronutrients and proteins are a major cause of a decreased immune function. Hence undernutrition makes especially geriatric subjects prone to infections. Undernutrition has been shown to be a risk factor for nosocomial pneumonia in a geriatric hospital ${ }^{(29)}$. On the other hand, infections can also cause a decrease in BMI in geriatric subjects with little nutritional reserve, which in turn, as a vicious cycle, enhances the probability of a more severe course of infection and of the acquisition of additional infections ${ }^{(2)}$.

However, also a high BMI or obesity has a clear effect on the immune response through immune mediators that lead to susceptibility to infections. Obesity has been shown to increase the risk especially for nosocomial infections and postoperative infections $^{(30)}$.

Underweight and obesity are the respective extremes on the BMI scale; however, some pathophysiological mechanisms occur in both cases. Underweight ${ }^{(23,31)}$ and obesity ${ }^{(31-33)}$ are both associated with frailty in geriatric subjects, and frailty is associated with infection and with inflammation ${ }^{(34,35)}$ Frailty is defined as a state of increased vulnerability to stressors $^{(35)}$ and therefore frailty is also associated with a loss of resilience against infectious agents ${ }^{(36)}$. Sarcopenia and sarcopenic obesity are common aspects of frailty in older subjects $^{(37)}$, and sarcopenia doubles the risk of nosocomial infections ${ }^{(38)}$. So, frailty and chronic inflammation can be the common factors associated with the higher proportion of infectious diseases in underweight as well as obese patients. Functional impairment in nursing home residents can lead to a higher risk of infections ${ }^{(22)}$. On the other hand, infectious diseases can cause functional impairment ${ }^{(39)}$ and frailty in older individuals.

A limitation of the present study is its retrospective design. The change of BMI during the observation period of up to 20 months could not be taken into account. Since weight loss is included in the operational definition of the concept of frailty, the influence of a change of body weight over time on the risk of infections should be of particular interest in future research. The non-standardised measurement of 
body weight and body height can lead to possible inaccuracies in the calculation of BMI; however, the weight is likely to be correct to within a few $\mathrm{kg}$, and bias from the non-standardised measurements is limited. The influence of nutrition treatment on the development of infections could not be observed, since there were no relevant data at the time of analysis. The use of BMI for classifying the nutritional status of elderly subjects does not take into account influences on body height such as osteoporosis, assessment of the compartments, fat or fat-free mass, that contribute to a high or a low body weight and as a consequence to BMI. Additionally, BMI does not take into account the role of fat distribution. The amount of observed person-time differs in the four BMI strata. This neither affects the incidence rates nor the incidence risk ratios. However, the number of obese subjects was clearly lower compared with subjects in other BMI strata, which results in large $\mathrm{CI}$ in this BMI stratum. This was especially marked in men, where the total number of subjects was already low; hence sex-specific conclusions based on our data are limited. Further research will be necessary to assess the influence that other factors related to nutritional status, such as body composition, have on the incidence of infections. The role of frailty and chronic inflammation in connection with BMI, nutritional status and the incidence of infections should be clarified further. Furthermore, the effects of intervention in order to optimise the nutritional status or to achieve a BMI of $24-27.9 \mathrm{~kg} / \mathrm{m}^{2}$ - identified as the BMI category with the lowest risk for infections in geriatric subjects - require further research.

Despite potential limitations of the present study, the results show a clear association between BMI and the risk of infections in institutionalised geriatric patients. The lowest risk in this population occurs in the 'overweight' (according to the WHO and National Institutes of Health categories) subjects. A lower BMI and obesity both increase the risk of infections.

\section{Acknowledgements}

We would like to thank both the medical and nursing staff of the 'Haus der Barmherzigkeit' for making the present study possible. There were no sources of funding for the present study.

All authors made substantial contributions to the intellectual content of the manuscript and approved the final version. T. E. D. developed the study concept, developed the hypotheses, interpreted the results and drafted the manuscript. F. S. performed statistical analyses and interpreted the data. A. K. was involved in the development of electronic patients' charts, and contributed to the study concept and manuscript revision. W. F. and A. R. interpreted the data and were involved in manuscript revision. C. G. contributed to the study concept, data interpretation and manuscript revision.

The authors do not have any conflicts of interest.

\section{References}

1. Richards CL Jr (2007) Infection control in long-term care facilities. J Am Med Dir Assoc 8, Suppl. 3, S18-S25.

2. Gavazzi G \& Krause KH (2002) Ageing and infection. Lancet Infect Dis 2, 659-666.
3. Furman CD, Rayner AV \& Tobin EP (2004) Pneumonia in older residents of long-term care facilities. Am Fam Physician 70, $1495-1500$

4. Locher JL, Roth DL, Ritchie CS, et al. (2007) Body mass index, weight loss, and mortality in community-dwelling older adults. J Gerontol A Biol Sci Med Sci 62, 1389-1392.

5. Eiben G, Dey DK, Rothenberg E, et al. (2005) Obesity in 70 -year-old Swedes: secular changes over 30 years. Int J Obes 29, 810-817.

6. Lapane KL \& Resnik L (2005) Obesity in nursing homes: an escalating problem. J Am Geriatr Soc 53, 1386-1391.

7. Grabowski DC \& Ellis JE (2001) High body mass index does not predict mortality in older people: analysis of the Longitudinal Study of Aging. J Am Geriatr Soc 49, 968-979.

8. Weiss A, Beloosesky Y, Boaz M, et al. (2008) Body mass index is inversely related to mortality in elderly subjects. $J$ Gen Intern Med 23, 19-24.

9. Heiat A, Vaccarino V \& Krumholz HM (2001) An evidence-based assessment of federal guidelines for overweight and obesity as they apply to elderly persons. Arch Intern Med 161, 1194-1203.

10. Davison KK, Ford ES, Cogswell ME, et al. (2002) Percentage of body fat and body mass index are associated with mobility limitations in people aged 70 and older from NHANES III. $J$ Am Geriatr Soc 50, 1802-1809.

11. Jensen GL (2005) Obesity and functional decline: epidemiology and geriatric consequences. Clin Geriatr Med 21, 677-687.

12. Zizza CA, Herring A, Stevens J, et al. (2002) Obesity affects nursing-care facility admission among whites but not blacks. Obes Res 10, 816-823.

13. PaMeDo (2009) Papierunterstützende Medizinische Dokumentation http://www.pamedo.at (accessed December 2009).

14. World Health Organization (2000) Obesity: Preventing and Managing the Global Epidemic. Report of a WHO Convention, Geneva, 1999. WHO Technical Report Series no. 894. Geneva: WHO.

15. Anonymous (1998) Clinical guidelines on the identification, evaluation, and treatment of overweight and obesity in adults - the evidence report. Obes Res 6, Suppl. 2, 51S-209S.

16. Calle EE, Thun MJ, Petrelli JM, et al. (1999) Body-mass index and mortality in a prospective cohort of U.S. adults. $N$ Engl J Med 341, 1097-1105.

17. Zhu S, Heo M, Plankey M, et al. (2003) Associations of body mass index and anthropometric indicators of fat mass and fat free mass with all-cause mortality among women in the first and second National Health and Nutrition Examination Surveys follow-up studies. Ann Epidemiol 13, 286-293.

18. Flegal KM, Graubard BI, Williamson DF, et al. (2007) Causespecific excess deaths associated with underweight, overweight, and obesity. JAMA 298, 2028-2037.

19. Zajacova A (2008) Shape of the BMI-Mortality Association by Cause of Death Using Generalized Additive Models: NHIS 1986-2002. Population Studies Center Research Report no. 08-639. Ann Arbor, MI: University of Michigan, Institute for Social Research.

20. Paillaud E, Herbaud S, Caillet P, et al. (2005) Relations between undernutrition and nosocomial infections in elderly patients. Age Ageing 34, 619-625.

21. Yoshikawa TT, Nicolle LE \& Norman DC (1996) Management of complicated urinary tract infection in older patients. $J \mathrm{Am}$ Geriatr Soc 44, 1235-1241.

22. Moro ML, Mongardi M, Marchi M, et al. (2007) Prevalence of long-term care acquired infections in nursing and residential homes in the Emilia-Romagna Region. Infection 35, 250-255.

23. Challa S, Sharkey JR, Chen M, et al. (2007) Association of resident, facility, and geographic characteristics with chronic undernutrition in a nationally represented sample of older residents in U.S. nursing homes. J Nutr Health Aging 11, 179-184. 
24. Kagansky N, Berner Y, Koren-Morag N, et al. (2005) Poor nutritional habits are predictors of poor outcome in very old hospitalized patients. Am J Clin Nutr 82, 784-791.

25. Soeters PB, Reijven PL, van Bokhorst-de van der Schueren MA, et al. (2008) A rational approach to nutritional assessment. Clin Nutr 27, 706-716.

26. Soeters PB \& Schols AM (2009) Advances in understanding and assessing malnutrition. Curr Opin Clin Nutr Metab Care 12, 487-494.

27. Janssens JP (2005) Pneumonia in the elderly (geriatric) population. Curr Opin Pulm Med 11, 226-230.

28. Allison SP (2000) Malnutrition, disease, and outcome. Nutrition 16, 590-593.

29. Rothan-Tondeur M, Meaume S, Girard L, et al. (2003) Risk factors for nosocomial pneumonia in a geriatric hospital: a control-case one-center study. J Am Geriatr Soc 51, 997-1001.

30. Falagas ME \& Kompoti M (2006) Obesity and infection. Lancet Infect Dis 6, 438-446.

31. Woods NF, LaCroix AZ, Gray SL, et al. (2005) Frailty: emergence and consequences in women aged 65 and older in the Women's Health Initiative Observational Study. J Am Geriatr Soc 53, 1321-1330.

32. Blaum CS, Xue QL, Michelon E, et al. (2005) The association between obesity and the frailty syndrome in older women: the Women's Health and Aging Studies. J Am Geriatr Soc 53, 927-934.
33. Villareal DT, Banks M, Siener C, et al. (2004) Physical frailty and body composition in obese elderly men and women. Obes Res 12, 913-920.

34. Schmaltz HN, Fried LP, Xue QL, et al. (2005) Chronic cytomegalovirus infection and inflammation are associated with prevalent frailty in community-dwelling older women. $J \mathrm{Am}$ Geriatr Soc 53, 747-754.

35. Walston J, Hadley EC, Ferrucci L, et al. (2006) Research agenda for frailty in older adults: toward a better understanding of physiology and etiology: summary from the American Geriatrics Society/National Institute on Aging Research Conference on Frailty in Older Adults. $J$ Am Geriatr Soc 54, 991-1001.

36. Varadhan R, Seplaki CL, Xue QL, et al. (2008) Stimulusresponse paradigm for characterizing the loss of resilience in homeostatic regulation associated with frailty. Mech Ageing Dev 129, 666-670.

37. Zamboni M, Mazzali G, Fantin F, et al. (2008) Sarcopenic obesity: a new category of obesity in the elderly. Nutr Metab Cardiovasc Dis 18, 388-395.

38. Cosquéric G, Sebag A, Ducolombier C, et al. (2006) Sarcopenia is predictive of nosocomial infection in care of the elderly. Br J Nutr 96, 895-901.

39. Büla CJ, Ghilardi G, Wietlisbach V, et al. (2004) Infections and functional impairment in nursing home residents: a reciprocal relationship. J Am Geriatr Soc 52, 700-706. 